\title{
Studying the thermal field dynamics in the forest harvesting sites
}

\author{
Vladimir Khamedov * \\ Yugra State University, Khanty-Mansiysk, 628012, Russia
}

\begin{abstract}
The article presents the results of the investigation of thermal field dynamics in the forest harvesting sites with the Landsat 8 satellite images in a long Infrared range. The temporary (annual and seasonal) dependences of the forest floor temperature in the harvesting sites are studied. The dependence of the forest floor temperature condition in the harvesting site on the area of the site is considered. The method to detect the sites strewn with the forest residues by using the images in a near Infrared range is described.
\end{abstract}

Keywords: space images; IR thermal image; Landsat-8; forest logging residues; the way of detection; fire danger period.

Satellite image data in infrared (IR) part of the spectrum are widely used for studying thermal contrasts of terrestrial landscapes. Special attention is given to studying "urban heat islands" [1-5]. Studying thermal regularities of the forest territories providing heat and water regulating functions is also very important. There are entire papers dedicated to studying forest temperature conditions, for example [6-7]. Forest temperature conditions are exposed to the influence of various technogenic factors, such as forest harvesting. Forest harvesting changes microclimatic conditions raising air temperature in comparison with a microclimate under a forest canopy. Temperature condition and air humidity fluctuate much stronger in the forest harvesting sites than under a forest canopy [8]. The research of temperature dependences in the forest harvesting sites will contribute to the solution of the tasks of forest rational exploitation.

The study area was located within the territory of Khanty-Mansi Autonomous Okrug, which has considerable forest resources. Forests cover an area of about 50,41 million hectares $(6,2 \%$ of the total forest area in Russia) with the planting stock of 3133,14 million $\mathrm{m}^{3}$. More than 130 companies and entrepreneurs are involved in logging business. By January 1, 2018 there have been signed 108 forest logging agreements. The total annual amount of harvesting wood on lease contracts is 2876,21 thousand $\mathrm{m}^{3}$, and the area of forests transferred to leasers is about 2812,085 thousand hectares.

This paper examines the features of thermal field dynamics for the forest harvesting sites obtained with the Landsat 8 spacecraft in a long Infrared range and also the method of detecting the sites strewn with the forest residues by using the images in a near Infrared range. The site of 113800 hectares located in a southwest part of the district has been chosen as a study area.

\footnotetext{
* Corresponding author: khamedov.vladimir@gmail.com
} 


\section{Long range Infrared imaging}

The thermal field dynamics was investigated in 22 forest harvesting sites of different area located within the borders of the test site. The minimum size of harvesting sites was 2,27 hectares, the maximum $-26,97$ hectares. The research was conducted for the time period from 2014 to 2017.

Sets of space images used for the research are presented in table 1.

Table 1. Frames from orbiting satellites made in different periods

\begin{tabular}{|c|c|c|}
\hline $\begin{array}{c}\text { Year of } \\
\text { imaging }\end{array}$ & Frame & $\begin{array}{c}\text { Time of imaging, } \\
\text { hour. (UTM) }\end{array}$ \\
\hline 2014 & LC08_L1TP_162017_20140703_20170421_01_T1 & $06: 48$ \\
\hline 2015 & LC08_L1TP_162018_20150722_20170406_01_T1 & $06: 47$ \\
\hline 2016 & LC08_L1TP_162018_20160606_20170324_01_T1 & $06: 47$ \\
\hline 2017 & LC08_L1TP_161018_20170618_20170629_01_T1 & $06: 42$ \\
\hline
\end{tabular}

Terrestrial radiation or thermal infrared radiation is determined by the temperature and composition of the radiating objects displayed on the satellite image. The surface radiation temperature for each image is reconstructed based on the spectral radiation intensity which was recorded by the imaging device [9].

The calculated mean instantaneous temperatures within and beyond (background value) the borders of forest harvesting sites by years are presented in table 2 . The background value was calculated as the arithmetic mean of the frame temperature, excluding cloudy areas and forest harvesting sites. The value of air temperature at an altitude of 2 meters above the Earth's surface was available from the nearby weather station in the village of Leushi (WMO ID 28064), located $23 \mathrm{~km}$ to the center of the test site. For all years, the temperature values recorded by the weather station at 11:00 local time were used

Table 2. The measured values of the surface temperatures in different years

\begin{tabular}{|c|c|c|c|c|c|}
\hline \multirow{2}{*}{ 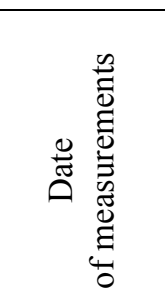 } & \multirow{2}{*}{ 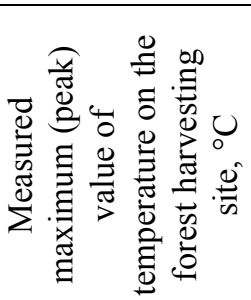 } & \multicolumn{2}{|c|}{$\begin{array}{l}\text { Measured mean } \\
\text { temperature, }{ }^{\circ} \mathrm{C}\end{array}$} & \multirow{2}{*}{ 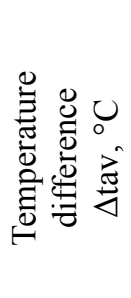 } & \multirow{2}{*}{ 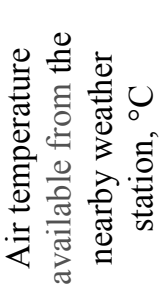 } \\
\hline & & $\begin{array}{c}\text { Forest } \\
\text { harvesting } \\
\text { sites }\end{array}$ & $\begin{array}{l}\text { Background } \\
\text { value }\end{array}$ & & \\
\hline 03.07 .2014 & 30,31 & 24,36 & 19,22 & 5,15 & 20,7 \\
\hline 22.07 .2015 & 26,47 & 22,91 & 20,57 & 2,34 & 23,2 \\
\hline 06.06 .2016 & 26,74 & 21,36 & 18,87 & 2,44 & 19,4 \\
\hline 18.06 .2017 & 26,11 & 22,39 & 19,87 & 2,52 & 22,2 \\
\hline
\end{tabular}

The calculated value of temperature difference between the mean temperature within the borders of the forest harvesting site and the background value of the temperature is shown in figure 1.

In the first year of measurements the mean temperature difference between the forest harvesting site and surrounding background was $5,15{ }^{\circ} \mathrm{C}$. The temperatures leveled off in 
the next years with the mean difference $2,43{ }^{\circ} \mathrm{C}$. The total absence or partial forest litter destruction, open drylands, logging residues on the forest harvesting sites are the most likely causes for the anomaly in the first year. Then, in the course of the constructive process, temperatures on the forest harvesting sites leveled off.

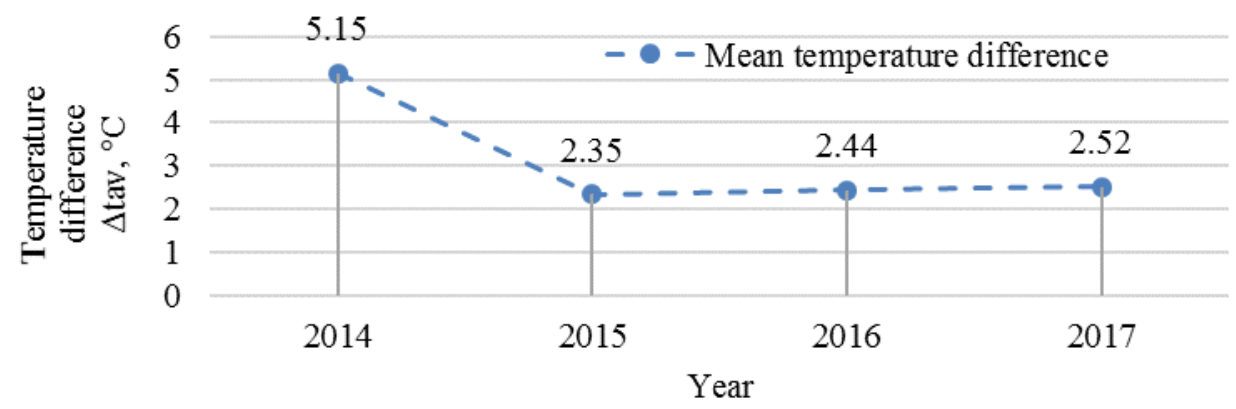

Fig. 1. Dynamic analysis of the mean temperature difference between the forest harvesting site and the background value

The dependence of maximum (peak) surface temperatures within the borders of the forest harvesting site on the area is presented in figure 2 .

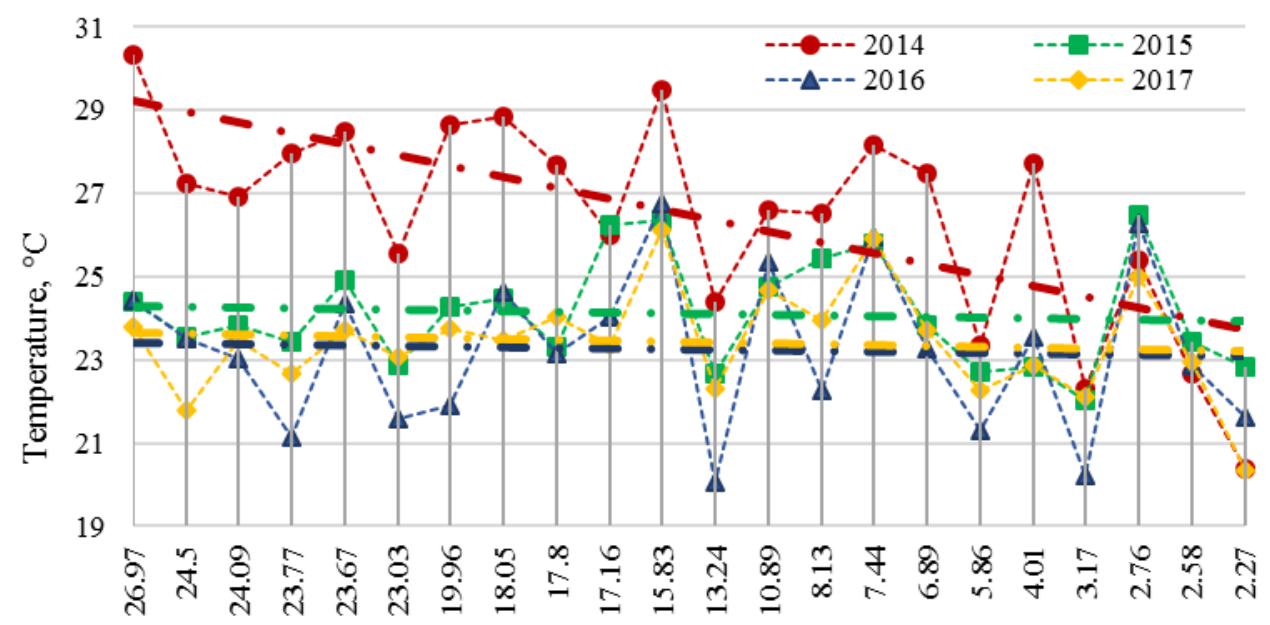

The area of the forest harvesting sites, hectares

Fig. 2. Dependence of surface temperature in forest harvesting sites on the area

In the first year there was marked positive correlation between the surface temperature in the forest harvesting site and the area of the site (the red line on the diagram). In the next years this dependence remained, however it was not so significant.

Seasonal dynamics of surface temperature in the forest harvesting sites was examined on the example of 71 sites in the period of time from January to December, 2017. The results of studying seasonal dependence of temperature difference are presented in table 3 , and graphically in figure 3 . 


\section{Near range Infrared imaging}

Some amount of biomass is often left on sites after harvesting operations (i.e. branches, tops, stumps). According to Fire safety rules it is prohibited to leave logging residues on the harvesting sites during the fire danger period [10]. Now space imagery of high spatial resolution or aerial photographs are used for detecting the sites with the logging residues. The logging residues are visually interpreted on such photographs. However, images of high spatial resolution have, as a rule, a limited swath width and cost a lot.

Table 3. Mean temperature within the borders of forest harvesting sites and its background value in $2017, \mathrm{t}^{\circ} \mathrm{C}$.

\begin{tabular}{|c|c|c|c|c|c|c|c|c|c|c|}
\hline $\begin{array}{c}\text { Date } \\
\text { of measurements }\end{array}$ & 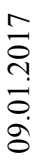 & 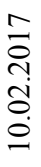 & 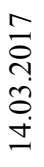 & 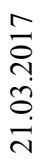 & 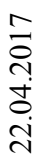 & $\begin{array}{l}\text { a } \\
\text { ì } \\
\text { ñ } \\
\text { i. } \\
0\end{array}$ & $\begin{array}{l}\text { aे } \\
\text { तु } \\
\text { o. } \\
\dot{d}\end{array}$ & 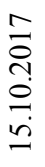 & 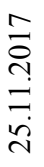 & 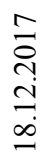 \\
\hline $\begin{array}{l}\text { Mean temperature } \\
\text { within the borders } \\
\text { of the forest } \\
\text { harvesting site, }{ }^{\circ} \mathrm{C}\end{array}$ & Fे & 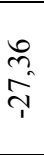 & $\begin{array}{l}\mathscr{S} \\
+ \\
+\end{array}$ & $\stackrel{\infty}{\sim}$ & $\bar{\sigma}$ & $\bar{n}$ & $\stackrel{2}{\infty}$ & $\begin{array}{l}n \\
m \\
m \\
m\end{array}$ & 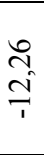 & $\frac{\infty}{\infty}$ \\
\hline $\begin{array}{l}\text { Mean background } \\
\text { temperature }{ }^{\circ} \mathrm{C}\end{array}$ & 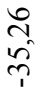 & $\begin{array}{l}\stackrel{2}{\grave{T}} \\
\stackrel{1}{1}\end{array}$ & $\begin{array}{l}\text { ते } \\
\text { in }\end{array}$ & $\stackrel{i}{i}$ & $\begin{array}{l}0 \\
+ \\
i \\
i\end{array}$ & $\begin{array}{l}\infty \\
\infty \\
\sim \\
\sim\end{array}$ & $\begin{array}{l}\bar{\sigma} \\
\pm \\
\pm\end{array}$ & $\frac{m}{m}$ & in & $\begin{array}{l}\mathbb{J} \\
\frac{m}{1}\end{array}$ \\
\hline $\begin{array}{c}\text { Temperature } \\
\text { difference } \\
\Delta \mathrm{t},{ }^{\circ} \mathrm{C}\end{array}$ & $\stackrel{+}{n}$ & $\begin{array}{l}8 \\
0 \\
0\end{array}$ & fó & $\frac{2}{\hat{0}}$ & $\stackrel{\cong}{\cong}$ & [ֶ, & $\begin{array}{l}\infty \\
n \\
m \\
m\end{array}$ & $\begin{array}{l}\tilde{N} \\
\tilde{o}\end{array}$ & तै & $\frac{ \pm}{i}$ \\
\hline
\end{tabular}

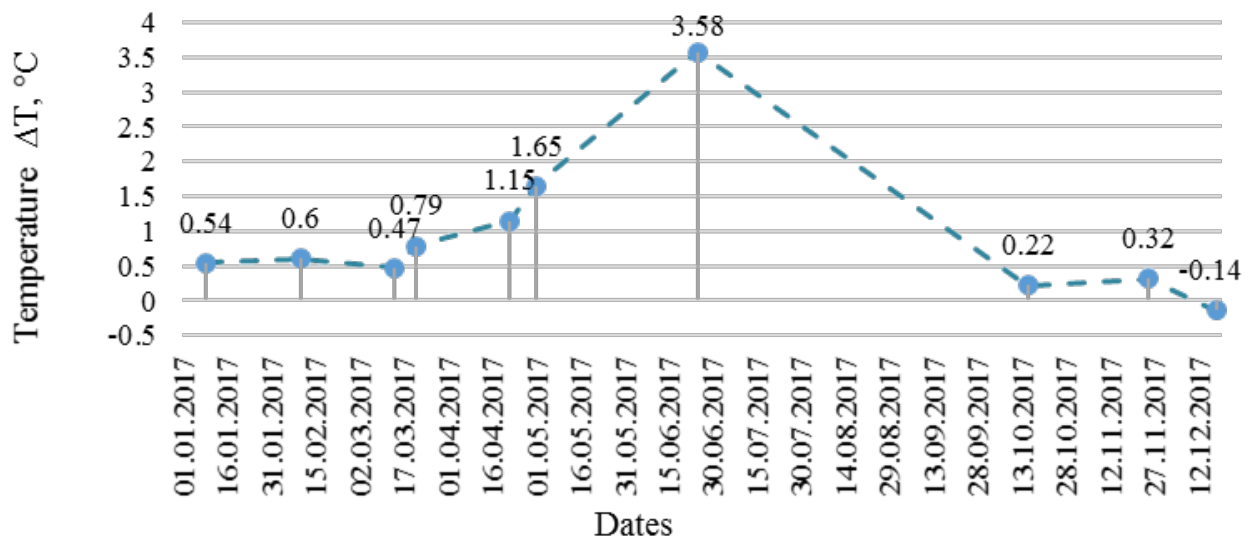

Fig. 3. Seasonal dependence of the mean temperature difference in the forest harvesting sites

During the spring thaw period the sites with the logging residues can be found by multispectral space images in the Infrared range [11], according to the Kirchhoff's radiation law, due to different surface temperatures on the sites. When snow cover melts in this time of the year the logging residues are seen on space images as thermal anomalies in the near infrared range. The difference in brightness between the pats of the image is caused by various albedo of the warmed sites.

A multispectral image for interpreting the sites with the logging residues can be obtained with the OLI instrument of Landsat 8, RGB combination (7-5-3). 
In figure 4 fragments of space images produced by Landsat- 8 at different times in the Infrared range on the forest harvesting site near the settlement of Leushi, Kondinsk Region, Khanty-Mansi Autonomous Okrug are presented. A collection of images allows to monitor the dynamics of forest harvesting sites appearance and the character of their thermal radiation. The total area of the forest harvesting site represented on the top part of the image is 13,27 hectares. The area of the site was formed in the following order: the northeast part with an area of around 4,3 hectares was cut down in a time interval between January 9, 2017 and January 25, 2017 (LC81610182017025LGN00). The northwest (the area of 4,81 hectares) and the southeast part (1,94 hectares) - in the period of time between January 25 , 2017 and February 10, 2017 (LC81610182017041LGN00). The southwest part with an area of 2,22 hectares - in the period of time between February 10, 2017 and March 14, 2017 (LC81610182017073LGN00).

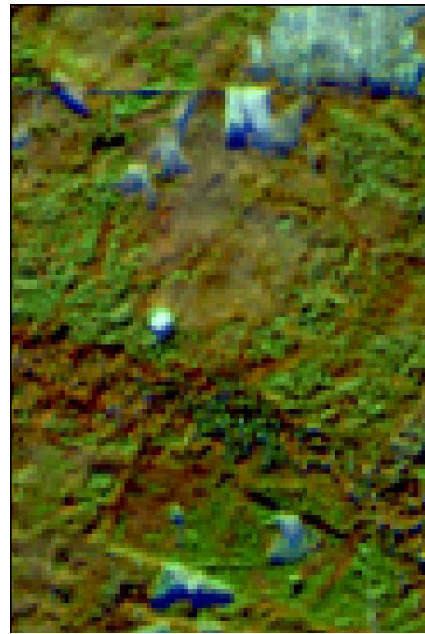

$\mathrm{a}$

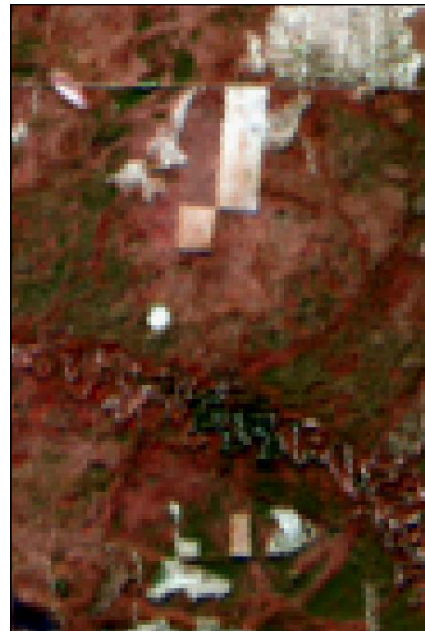

d

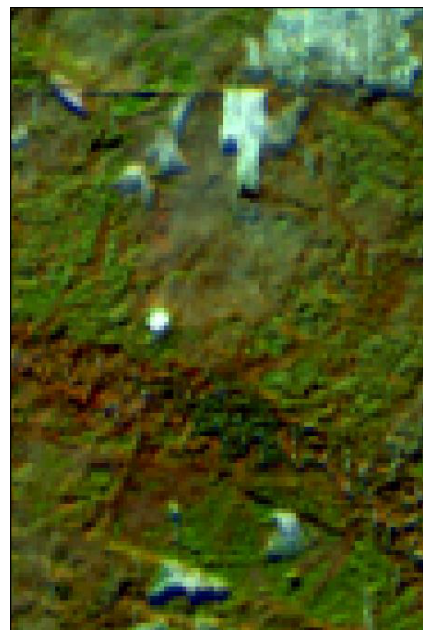

b

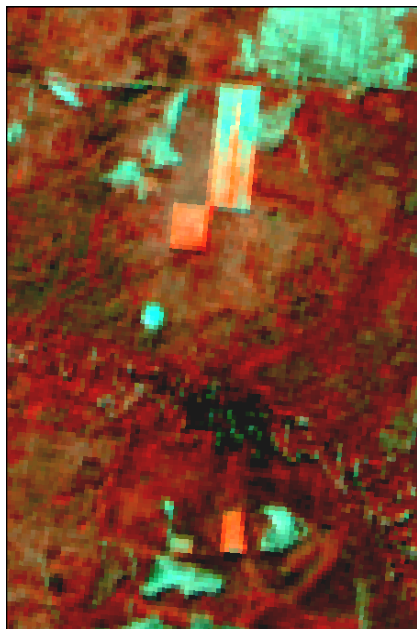

e

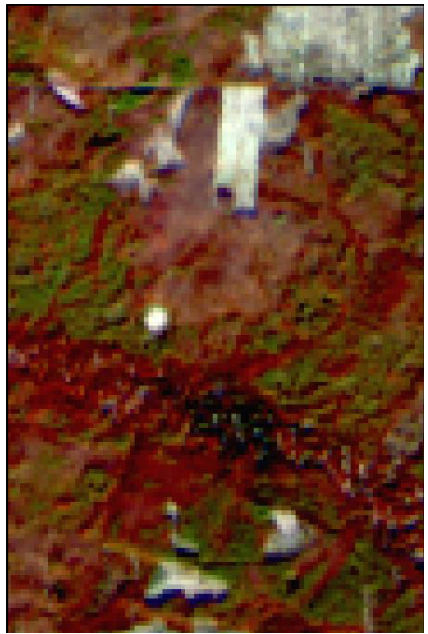

C

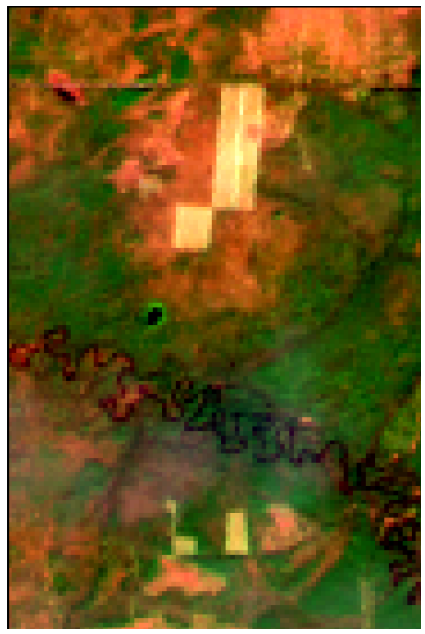

f

Fig. 4. Images of forest harvesting sites with logging residues produced in the Infrared range at different times (combination of spectral bands 7-5-3): a - January 9, 2017; b - January 25, 2017; c February 10, 2017; d-March 14, 2017; e - March 21, 2017; f-May 1, 2017 
The site with an area of 6,83 hectares adjoining from the South was cut down between February 10, 2017 and March 14, 2017. The site to the south with an area of 3,86 hectares was cut down between February 10, 2017 and March 14, 2017.

Consider the image of forest harvesting sites shown in figure 4. The image was obtained on March 21, 2017 during the initial stage of snow melting. Objects with thermal anomalies - the sites with the logging residues are depicted with red. On the site of 13,27 hectares the logging residues collected into piles are seen.

Figure 5 shows the combined diagrams of the current snow depth and the air temperature available from the nearby weather station in the village of Leushi (source: http://rp5.ru). For this territory positive dynamics of snow melting was observed from February 21, 2017. With an increase in temperature, sites with the logging residues warmed up for a shorter period of time. The site warmed up as temperature increased and snow cover melted. From April 6, 2017 the depth of snow cover decreased sharply, complicating detection of sites with the logging residues (figure 4-f).

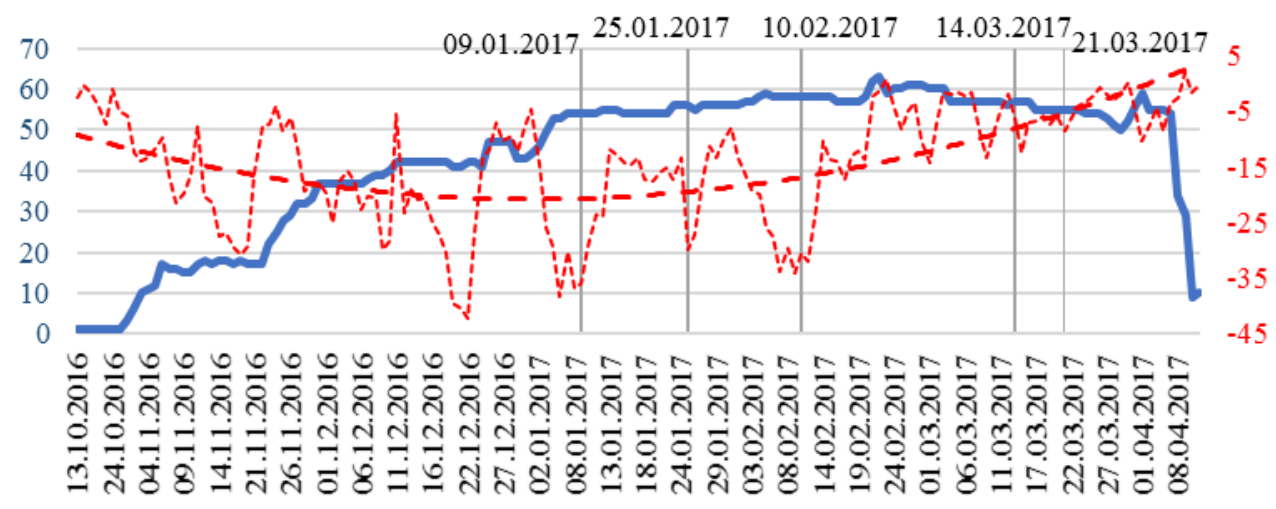

snow cover depth, sm ------- air temperature, $\mathrm{C}$

Fig. 5. Dynamics of snow cover depth and air temperature in the observation area

The method presented can be used to detect sites with the logging residues in the process of interpreting space images with an average spatial resolution in the period of intensive spring snow melting. This method allows to find the forest harvesting sites with the logging residues left in the previous winter period, define the borders and the areas of those sites. The data collected can be used for carrying out complex satellite monitoring of forest ecosystems $[12,13]$ and for operational fire danger forecasting in the observation areas just before the beginning of the fire danger period.

\section{Conclusion}

Studying the thermal field dynamics in the forest harvesting sites helps to ensure rational exploitation of forest resources by maintaining the proper ratio between the amount of forest exploitation and the conservation-oriented policies. The method suggested to detect the forest harvesting sites with the logging residues is based on the use of space images with an average spatial resolution. The use of Infrared for detecting the sites with the logging residues has seasonal character. Therefore the method suggested can be applied in the period of intensive snow cover melting. The possibility of detecting and mapping the 
sites with the logging residues just before the beginning of a fire danger season can be referred to the practical importance of the research. This will allow to take the measures necessary for decreasing fire danger in the forest territories before the fire danger season.

\section{References}

1. Oki K., Omasa K. Technique for Mapping Thermal Infrared Radiation Variation Within Land Cover // IEEE Transactions on Geoscience and Remote Sensing. 2003. Vol. 41. № 6. P. 1521-1524.

2. Gluch R., Quattrochi D.A., Luvall J.C. A multi-scale approach to urban thermal analysis //Remote Sensing of Enviromment. 2006. № 104. P. 123-132.

3. Ilyin Yu.A., Chufarova N.E. Complex analysis of thermal infrared imagery of the earth surface//News of higher educational institutions. Geodesy and aerial photography. №. $2 .-2011-$ P. $37-40$.

4. Preston N.E. Features of spatial distribution of radiation temperature for different landscapes on thermal infrared images//News of higher educational institutions. Geodesy and aerial photography. - № . 5. - 2012 - Page 63 - 66.

5. Gryshchenko M.Yu. Application of thermal ETM+ imagery for studying Moscow urban heat island /Modern problems of remote sensing of Earth from space. 2012. V . 9. № . 4. Page 95-101.

6. Sakharov M.I. Dependence of soil temperature on the character of forest cover//"Soil science". 1948. № 3. - Page 5-13.

7. Arkhipova E.P. The Effect of of forest belts on the soil temperature profile//Works of the main geophysical observatory of A.I. Voyeykov. 1952. Issue 36 (98). Page 27-38.

8. Kozlov V.M. The Effect of Logging on Habitat and Populations of Game Animals of the European Taiga monograph. - Kirov: Vyatka GSHA, 2010. - 150 p.

9. Chen Y., Sui D. Z., Fung T., Dou W."Fractal analysis of the structure and dynamics of a satellite-detected urban heat island"//International Journal of Remote Sensing, 28, № 10, 20 May 2007, 2359-2366.

10. The resolution of the Government of the Russian Federation dated June 30, 2007 №417 "Fire safety rules" Access mode: The GARANT Legal Information Resource

11. Khamedov V. A. Detection of forest sites with logging residues by medium spatial resolution satellite imagery//Materials of the III All-Russian scientific and practical conference "Geoinformation Technologies for the Solution of problems of Rational Environmental Managemen" Khanty-Mansiysk. 2017, 72-75.

12. Khamedov V. A., Mazurov B.T. Development of methodical issues for the creation of forest ecosystems satellite monitoring system in conditions of oil and gas complex influence in the territory of Western Siberia//Vestnik SGUGiT . 2015. Issue 3 (31), 1631.

13. Mazurov B.T., Avrunev E.I., Khamedov V.A.. Operational monitoring of forests in northern regions using optical and radar space imagery//Modern problems of remote sensing of the Earth from space 2017. V. 14. No. 4, 103-111. 